\title{
0 corrência de Klebsiella pneumoniae e outros coliformes em sabão neutro líquido utilizado em um berçário de hospital
}

\author{
Ana Cristina Azevedo M oreira ${ }^{1}$ \\ José Luiz M oreira de Carvalho ${ }^{2}$
}

\begin{abstract}
Resumo
Foi constatado, no berçário de um hospital da rede pública de Salvador, um surto de infecção hospitalar causado por K lebsiella pneumoniae. Para detectar a origem da infecção, foram realizadas análises microbiológicas em diversas possíveis fontes decontaminação exógenas. Verificou-se, na água com sabão, utilizada no banho dos recém-nascidos, a presença deK Iebsi ella pneumoniaee outros coliformes. N ão tendo sido constatada contaminação na água que servia ao berçário, foram examinadas várias amostras do sabão neutro líquido utilizado, sendo nelas isolados K lebsiella pneumoniae, Enterobacter doacaee outros col iformes. Amostras de sabão de diferentes lotes foram então analisadas, constatando-se contaminação apenas no loteenviado ao hospital. 0 fabricanteatribuiu a contaminação desselote ao uso deágua não tratada, de procedência desconhecida, no processo de fabricação do sabão. 0 s resultados obtidosnessa investigação apontam o sabão neutro líquido como uma posśvel fonte deinfecção hospitalar, normalmentenão consideradacomo tal, e mostram os riscos que a não observância de boas práticas de fabricação podem acarretar para os usuários de produtos dehigieneelimpeza.
\end{abstract}

Palavras-chave: Klebsiella pneumoniae- infecção hospitalar, sabão neutro, coliforme- contaminação.

\section{INTRO DUÇÃO}

N os últimos anos, a prevenção e o controle das infecções hospitalares vêm ganhando cada vez maior importância. Fontes oficiais afirmam que morrem cerca de 100 mil pessoas por ano no Brasil, vítimas destas infecções (BRASIL, 2001).

As infecções hospitalares podem ter origem endógena, quando causadas pela própria microbiota residente do paciente, ou exógena, causadas por microrganismos veiculados por alimentos, água, vetores ou por medicamentos contaminados durante a sua produção ou ma- nipulação hospitalar (GO N TIJO FILHO et al., 1984).

Entre as infecções hospitalares, aquelas que ocorrem no período neonatal são as mais freqüentes e severas. A prevenção e o controle desses processos infecciosos ainda hoje constituem verdadeiro desafio para os profissionais envolvidos nessa área (FAZIO JR; N O M URA; NOGUEIRA, 2000).

Surtos de infecção hospitalar causada por Klebsiella pneumoniae foram relatados por vários autores (PITREZ et al., 1982; MAGGI;

\footnotetext{
${ }^{1}$ Professora Adjunto. M estre em M icrobiologia. Instituto de Ciências da Saúde - U FBA. Professora Titular de M icrobiologia - U N EB.

Salvador - BA

${ }^{2}$ D outorando. Programa de Pós-graduação em Engenharia da Produção - UFSC ar. São Carlos - SP

Correspondência para / Correspondence to:

Ana Cristina Azevedo M oreira

D epartamento de Biointeração. Instituto de Ciências da Saúde - UFBA

Av. Reitor Miguel Calmon s/no. Vale do Canela

40.150-140. Salvador - BA - Brasil

Tel.: (71) 32458602

Fax: (71) 32458917

E-mail: crisazev@ufba.br
} 
SCHINDLER, 1990; ÁVILA FIGUEROA et al., 1999; SADER et al., 2001), determinando a prevalência de infecções hospitalares, os fatores de risco e a mortalidade associada a crianças hospitalizadas, Ávila Figueroa e colaboradores (1999) verificaram quea infecção mais freqüente era pneumonia, e o principal microrganismo causador, Klebsiella pneumoniae. Os principais fatores de infecção detectados, nesse caso, foram a exposição a cateteres intravenosos, a alimentação parenteral e a ventilação mecânica.

$\mathrm{N}$ as principais fontes exógenas de infecção hospitalar citadas por Fazio Jr., N omura e N ogueira (2000), estão o contato físico direto, o contato indireto via objetos contaminados, fluidos contaminados, e a via aérea. Pitrez e colaboradores (1982) descreveram dois surtos de infecção hospitalar com septicemia, numa enfermaria pediátrica, causada pela contaminação por Klebsiella e Enterobacter nos líquidos de infusão intravenosa administrados às crianças.

$D$ as medidas utilizadas para a prevenção das infecções hospitalares, a higienização das mãos é uma medida de inquestionável eficácia e baixo custo. 0 uso de sabões e ou anti-sépticos para essa prática deve se constituir em prática corriqueira para os profissionais de saúde (BRASIL, 1998).

O s sabões são produtos formados pela saponificação ou neutralização de óleos, gorduras, ceras e breus ou seus ácidos, com bases orgânicas ou inorgânicas. 0 sabão neutro é um sabão sem coadjuvantes, substancialmente isento de álcalis livres. É considerado como produto com risco mínimo (grau de risco 1) quando utilizado e se destina à limpeza corporal (CON SELHO NACIONAL DE SAÚDE, 1978; AGÊNCIA NACIONAL DE VIGILÂNCIA SAN ITÁRIA, 2000).

A pesar de serem produtos destinados à higiene corporal ou das mãos, anti-sepsia ou desinfecção, alguns estudos relataram contaminação microbiana em sabões, anti-sépticos ou desinfetantes. M iyagi, Timenetsky e Alterthum (2000) isolaram B. cepaceaee Serratia marcescens em desinfetantes de uso doméstico à base de quaternários de amônio. Em uma UTI neonatal, Reiss e colaboradores (2000) descreveram um surto de sepsis provocado pelo uso de desinfetante contaminado por Klebsiella oxytoca.
Há também alguns casos de contaminação microbiológica em sabão. Archibald e colaboradores (1997), investigando a fonte de in ${ }^{-}$ fecção em UTI neonatal causada por Serratia marcescens, encontraram a bactéria em sabão com $1 \%$ de cloroxilenol.

No Brasil, Levy (2000) relatou um surto de infecção hospitalar no qual se constatou a contaminação de sabão líquido por Enterobacter cloacae e Pseudomonas aeruginosa. Concluiu que a contaminação aconteceu no almoxarifado do hospital, quando se fracionava o sabão em frascos.

D urante um surto de pneumonia causada por Klebsiella pneumoniae na pediatria, setor de neonatos de um hospital da rede pública de Salvador, Bahia, procurou-se investigar reservatórios ou fontes da infecção hospitalar, tendo sido identificado como provável fonte de infecção o sabão neutro líquido utilizado no setor. 0 objetivo deste trabalho é apresentar os resultados dessa investigação.

\section{MATERIAIS E MÉTODOS}

Para detectar a origem da infecção, foram coletadas amostras em possíveis fontes de contaminação. Buscando avaliar a qualidade microbiológica da água utilizada no setor de pediatria e no hospital, foram coletadas cinco amostras de água em recipientes estéreis. Duas dessas amostras foram coletadas em torneiras das pias do berçário e as outras, no tanque geral do hospital, no ponto de entrada da água da rua para o hospital e na água destinada ao banho dos recém-nascidos, que estava misturada com um pouco de sabão neutro líquido. Após a realização das análises microbiológicas, foi constatada contaminação apenas na água do banho dos recém-nascidos misturada com 0 sabão. Posteriormente, foram analisadas três amostras do sabão neutro líquido, confirmando-se a contaminação do sabão. A Vigilância Sanitária foi então notificada, coletando outras amostras do produto em diferentes locais: almoxarifado do hospital, almoxarifado da Secretaria de Saúde e diretamente da fábrica, para serem realizadas novas análises.

O s sabões eram de dois tipos: com ou sem o corante rodamina B (Tetraetilrodamina 
- $\mathrm{C}_{28} \mathrm{H}_{31} \mathrm{Cl} \mathrm{N}{ }_{2} \mathrm{O}_{3}$, ou corante violeta básico 10).

Para a análise microbiológica das amostras de água e sabão, foi determinada a presença de coliformes totais e fecais pela técnica dos tubos múltiplos e número mais provável (N M P), em caldo lauril triptose, caldo lactosado bile verde brilhante e caldo E.C., incubados a $37^{\circ} \mathrm{C}$ e $44,5^{\circ} \mathrm{C}$, respectivamente, seguindo-se a identificação bioquímica dos coliformes isolados. Foi também realizada a contagem padrão de bactérias mesófilas heterotróficas em ágar plate count, semeando-se pela técnica do pour plate e incubando em estufa regulada a $37^{\circ} \mathrm{C}$ por 48 horas. $0 \mathrm{~s}$ resultados foram expressos em unidades formadoras de colônias (UFC).

A metodologia utilizada para as análises foi realizada de acordo com o Standard M ethods for the Examination of Water and Waste Water (AMERICAN PUBLIC HEALTH ASSOCIATIO N, 1975) e com Koneman e colaboradores (1997).

\begin{tabular}{|l|c|c|c|c|}
\hline Am ostras & $\begin{array}{c}\text { Bactérias mes6filas } \\
\text { heterotroficas } \\
\text { (UFClml) }\end{array}$ & $\begin{array}{c}\text { Coliformes } \\
\text { totais } \\
\text { (NMP/100 ml) }\end{array}$ & $\begin{array}{c}\text { Coliformes } \\
\text { fecais } \\
\text { (NMP/100 ml) }\end{array}$ & $\begin{array}{c}\text { Klebsiella } \\
\text { pneumoniae }\end{array}$ \\
\hline $\begin{array}{l}\text { Agua da pia 1 } \\
\text { (berçário) }\end{array}$ & - & - & - & - \\
\hline $\begin{array}{l}\text { Agua da pià } 2 \\
\text { (berḉrio) }\end{array}$ & - & - & - & - \\
\hline $\begin{array}{l}\text { Agua do banho } \\
\text { c/sabão neutro }\end{array}$ & $1,0 \times 10^{3}$ & $1,6 \times 10^{4}$ & - & + \\
\hline $\begin{array}{l}\text { Agua da entrada } \\
\text { darua }\end{array}$ & - & - & - & - \\
\hline $\begin{array}{l}\text { Agua do tanque } \\
\text { geral }\end{array}$ & - & - & - & - \\
\hline
\end{tabular}

Q uadro 1 - Pesquisa de coliformes, bactérias mesófilase Klebsiella pneumoniaeem amostras de água do hospital.

N ota: (-) Ausência, (t) Presença

\section{RESULTAD O S}

O s resultados obtidos nas análises das amostras de água provenientes das pias do berçário, tanque do hospital e entrada da rua, de monstraram ausência de bactérias mesófilas e coliformes totais e fecais. Já na água do banho dos recém-nascidos, onde havia sido misturado sabão neutro líquido, foram isoladas bactérias mesófilas, coliformes totais e, dentre esses, Klebsiella pneumoniae (QUADRO 1).

Constatada contaminação apenas na água com sabão e realizadas análises no sabão em uso e em embalagens fechadas foram obtidos os re sultados mostrados no Q uadro 2.

Os Q uadros 3 e 4, apresentam os resultados das análises realizadas no sabão neutro coletado pela Vigilância Sanitária em diversos locais, após ter sido constatada a contaminação no sabão do hospital.

$N$ as amostras de sabão, contaminadas por coliformes, contendo o corante rodamina, foi isolada e identificada em cultura pura apenas Klebsiella pneumoniae. A cepa era acapsulada. Já nas amostras do sabão sem o corante, contaminadas, foram isolados outros coliformes como Enterobacter cloacae, além de Klebsiella pneumoniae.

Considerando-se a análise do conjunto de amostras de sabão coletadas em diferentes locais, os resultados são vistos no Q uadro 5 .

Como se pode perceber, apenas nas amostras coletadas no próprio hospital, detectou-se contaminação do sabão.

Em relação às embalagens, constatou-se a ausência de rótulo e numeração do lote nas

\begin{tabular}{|l|c|c|c|c|}
\hline \multicolumn{1}{|c|}{ Amostras } & $\begin{array}{c}\text { Contagem de } \\
\text { bactérias } \\
\text { mesófilas/ml (UFC) }\end{array}$ & $\begin{array}{c}\text { Coliformes } \\
\text { totais } \\
\text { (NMP/100 ml) }\end{array}$ & $\begin{array}{c}\text { Coliformes } \\
\text { fecais } \\
\text { (NMP/100 ml) }\end{array}$ & $\begin{array}{c}\text { Klebsiella } \\
\text { pneumoniae }\end{array}$ \\
\hline $\begin{array}{l}\text { Sabão neutro em } \\
\text { uso }\end{array}$ & $7,1 \times 10^{4}$ & $1,6 \times 10^{4}$ & - & + \\
\hline $\begin{array}{l}\text { Sabão neutro do } \\
\text { berçário }\end{array}$ & $8,1 \times 10^{4}$ & $1,8 \times 10^{4}$ & - & + \\
\hline $\begin{array}{l}\text { Sabáo neutro da } \\
\text { enfermaria }\end{array}$ & $8,0 \times 10^{4}$ & $2,1 \times 10^{4}$ & & + \\
\hline
\end{tabular}

Q uadro 2 - Pesquisa de coliformes, bactérias mesófilas eK Iebsiella pneumoniaeem amostras de sabão neutro líquido utilizado no hospital

N ota: (-) Ausência, (+) Presença 


\begin{tabular}{|c|c|c|c|c}
\hline Amostras & Local de origem & $\begin{array}{c}\text { Contagcm de bactórias } \\
\text { mesófilas em placas } \\
\text { (UFC) }\end{array}$ & $\begin{array}{c}\text { Coliformes totais } \\
(\mathrm{NMP} / 100 \mathrm{ml})\end{array}$ & $\begin{array}{c}\text { Klebsiella } \\
\text { pnenmoniae }\end{array}$ \\
\hline 1 & Almoxarifado central & - & - & - \\
\hline 2 & Almoxarifado central & - & - & - \\
\hline 3 & Almoxarifado central & - & - & - \\
\hline 4 & Almoxarifado central & - & - & - \\
\hline 5 & Almoxarifado central & - & - & - \\
\hline 6 & Almoxarifado central & - & - & - \\
\hline 7 & Fábrica & - & - & - \\
\hline 8 & Fábrica & - & - & - \\
\hline
\end{tabular}

Q uadro 3 - Pesquisa de coliformes ebactérias mesófilas em amostras de sabão vindas da fábricae do almoxarifado central da Secretaria de Saúde.

N ota: (-) Ausência

\begin{tabular}{|c|c|c|c|c|}
\hline Amostras & Tipo de sabão & $\begin{array}{c}\text { Contagem de bactérias } \\
\text { mesófilas em placas } \\
(\mathrm{UFC} / \mathrm{ml})\end{array}$ & $\begin{array}{c}\text { Coliformes totais } \\
\text { (NMP/100 ml) }\end{array}$ & $\begin{array}{c}\text { Klebsiella } \\
\text { pneumoniae }\end{array}$ \\
\hline 1 & Sem corante & $1,0 \times 10^{4}$ & $8,0 \times 10^{3}$ & + \\
\hline 2 & Sem corante & $3,4 \times 10^{1}$ & $2,0 \times 10^{3}$ & + \\
\hline 3 & Sem corante & $2,5 \times 10^{4}$ & $1,6 \times 10^{4}$ & + \\
\hline 4 & Sem corante & $2,0 \times 10^{4}$ & $1,8 \times 10^{4}$ & + \\
\hline 5 & Sem corante & $5,6 \times 10^{1}$ & $5,0 \times 10^{3}$ & + \\
\hline 6 & Sem corante & $9,4 \times 10^{1}$ & $2,0 \times 10^{3}$ & + \\
\hline 7 & Sem corante & $2,0 \times 10^{1}$ & $2,0 \times 10^{3}$ & + \\
\hline 8 & Sem corante & $5,5 \times 10^{1}$ & $2,0 \times 10^{3}$ & + \\
\hline 9 & Sem corante & $1,1 \times 10^{3}$ & $2,0 \times 10^{3}$ & + \\
\hline 10 & Sem corante & $4,7 \times 10^{3}$ & $2,0 \times 10^{4}$ & + \\
\hline 11 & Com corante & $6,0 \times 10^{4}$ & $1,6 \times 10^{4}$ & + \\
\hline 12 & Com corante & $4,8 \times 10^{4}$ & $2,1 \times 10^{4}$ & + \\
\hline 13 & Com corante & $3,8 \times 10^{4}$ & $1,8 \times 10^{4}$ & + \\
\hline 14 & Com corante & $4,0 \times 10^{4}$ & $1,6 \times 10^{4}$ & + \\
\hline 15 & Com corante & $4,5 \times 10^{4}$ & $2,1 \times 10^{4}$ & + \\
\hline
\end{tabular}

Q uadro 4 - Pesquisa de coliformes emesófilas em amostras de sabão neutro líquido coletadas no almoxarifado do hospital.

N ota: (-) Ausência, (+) Presença

\begin{tabular}{|l|c|c|c|c|c|}
\hline \multicolumn{1}{|c|}{ Amostras } & $\begin{array}{c}\text { Quantidade } \\
\text { de amostras }\end{array}$ & $\begin{array}{c}\text { Bactérias } \\
\text { mesófilas }\end{array}$ & $\begin{array}{c}\text { Coliformes } \\
\text { totais }\end{array}$ & $\begin{array}{c}\text { Coliformes } \\
\text { fecais }\end{array}$ & $\begin{array}{c}\text { Klebsiella } \\
\text { pneumoniae }\end{array}$ \\
\hline $\begin{array}{l}\text { Sabão sem corante, do } \\
\text { hospital }\end{array}$ & 10 & + & + & - & + \\
\hline $\begin{array}{l}\text { Sabão com corante, do } \\
\text { hospital }\end{array}$ & 5 & + & + & - & + \\
\hline $\begin{array}{l}\text { Sabão com corante, o } \\
\text { almoxarifado central (S. } \\
\text { Saúde) }\end{array}$ & 6 & - & - & - & - \\
\hline $\begin{array}{l}\text { Sabão com corante, da } \\
\text { fábrica }\end{array}$ & 2 & - & - & - & - \\
\hline
\end{tabular}

Q uadro 5 - Presença/ausência de bactérias mesófilas e coliformes em amostras de sabão coletadas em diferentes locais.

N ota: (-) Ausência, (+) Presença 
unidades dos sabões analisados. Apenas na embalagem secundária (caixas de papelão usadas para 0 transporte), havia numeração dos lotes.

0 fabricante do sabão atribuiu a contaminação detectada nos lotes fornecidos ao hospital à utilização, na fabricação do sabão, de água coletada em caminhão pipa de procedência desconhecida, motivado pela falta de água tratada na fábrica. As unidades dos lotes de sabão contaminado foram recolhidas pela Vigilância Sanitária.

\section{ISC U SSÃO}

Semelhante a outros relatos descritos na literatura, os resultados obtidos neste trabalho também apontaram para uma fonte exógena, 0 sabão líquido utilizado no hospital, como possível agente de transmissão da infecção hospitalar em recém-nascidos. Porém não se pode afirmar que esse tenha sido o único agente causal da infecçãa nos neonatos, pois suas condições físicas e nutricionais já os predispunham à aquisição de infecções de diversas origens.

Pela característica do seu pH, neutro, e pela ausência de agentes antimicrobianos incorporados à sua fórmula, o sabão líquido permitiu a sobrevivência e o crescimento de diversos microrganismos, destacando-se Klebsiella pneumoniae. De acordo com Pelczar, Reid e Chan (1997), a maioria dos microrganismos cresce melhor em valores de pH entre 6,5 e 7,5. Provavelmente, os coliformes, dentre os quais Klebsiella pneumoniae, encontraram um ambiente propício à sua sobrevivência no sabão contaminado.

$\mathrm{N}$ os sabões que continham o corante Rodamina B, isolou-se apenas Klebsiella pneumoniae. Já nos sabões sem o corante, além dessa bactéria, cresceram outros coliformes. De acordo com Pelczar, Reid e Chan (1997), duas classes de corantes apresentam efeitos antimicrobianos: os derivados do trifenilmetano e alguns derivados da acridina. A Rodamina B é um corante utilizado em cosméticos e sabões para fins estéticos, não existindo menção de uma função antimicrobiana. Porém, neste caso, o corante poderia estar inibindo o crescimento de coliformes menos resistentes do que K Iebsiella pneumoniae.

As cepas isoladas do sabão com o corante eram acapsuladas. Sendo Klebsiella pneumoniae uma bactéria capsulada, essa modificação poderia ter sido provocada pelo corante. Ao contrário dos nossos resultados, Reiss e colaboradores (2000) isolaram, em desinfetante contaminado com Klebsiella oxytoca, formadora de cápsula, tendo os autores atribuído a resistência da bactéria ao desinfetante à presença da cápsula.

Embora o sabão neutro seja considerado como um produto com grau de risco mínimo, a alta contagem de bactérias mesófilas e coliformes obtida nos sabões do hospital os tornava de alto risco para os fins para os quais foram destinados, como para o banho de recémnascidos e higiene das mãos. $N$ esta investigação, notou-se o procedimento inadequado de utilizar um sabão sem rótulo no banho de recém-nascidos que apresentavam condições nutricionais e imunológicas deficientes e com baixo peso.

Considerando que foram analisadas amostras de sabão de lotes diferentes, coletadas em locais diferentes (hospital, almoxarifado central da Secretaria de saúde e fábrica), e que foi constatada a contaminação apenas nos lotes em uso no hospital, o problema da qualidade na fabricação do sabão aparentemente não era recorrente. Entretanto, a produção e a comercialização de sabão neutro líquido contaminado evidenciaram uma série de falhas no controle e na garantia da qualidade do produto.

A garantia da qualidade durante a fabricação, de acordo com a Agência $\mathrm{N}$ acional de Vigilância Sanitária (1997), envolve quase todas as operações da empresa para poder reduzir, eliminar e, o mais importante, prevenir alguma deficiência na qualidade. $\mathrm{No}$ caso do sabão neutro líquido contaminado, ficaram evidentes falhas no controle de qualidade do sabão, não apenas no controle do produto acabado, mas durante o processo de fabricação.

$\mathrm{N}$ a empresa, atribuíram a contaminação ao uso de água de caminhão-pipa, de proce- 
dência desconhecida, devido à falta d'água na fábrica. $\mathrm{A}$ água, segundo a Agência $\mathrm{N}$ acional de Vigilância Sanitária (1997), deve ter uma atenção particular, para assegurar a conformidade com as especificações do produto final, devendo ser monitorada regularmente quanto à sua qualidade química e microbiológica, de acordo com os procedimentos de produção, e ações corretivas devem ser tomadas no caso de qualquer anomalia.

Além de falhas no controle microbiológico da água e do sabão produzido, percebe-se um outro procedimento inadequado, no caso da rotulagem e da identificação dos lotes do produto. 0 s lotes eram identificados apenas nas caixas de papelão usadas como embalagem para o transporte, não ocorrendo o mesmo com as garrafas plásticas usadas como embalagens primárias (as que têm contato direto com o produto), o que dificulta a identificação e 0 isolamento de lotes contaminados quando as unidades são retiradas das caixas. A ausência de rótulo, além de prejudicar a identificação dos lotes, não ajuda a identificar a procedência e 0 conteúdo do produto, o que pode também implicar uso inadequado do mesmo.

U ma observação final deve ser feita sobre o procedimento de compra do hospital ou da rede hospitalar pública, em qure os produtos de menor custo são preferencialmente adquiridos. Q uando baseadas apenas no menor preço, as licitações podem implicar procedimentos de fabricação inadequados pelas empresas concorrentes, visando a reduzir custos, para poder oferecer um preço menor. 0 uso de matérias-primas de qualidade inferior ou de mão-de-obra sem a devida capacitação pode diminuir o preço, em detrimento da qualidade do produto final. U ma garantia de qualidade do produto deve ser exigida, pois, pelo grande volumee pela grande variedade de produtos diferentes que um hospital deve comprar, torna-se difícil inspecionar a qualidade de tudo o que é adquirido.

\section{CONCLUSÕES}

As fontes exógenas de infecção hospitalar podem ter importância considerável na transmissão de infecções, principalmente em se tratando de recém-nascidos de alto risco. $0 \mathrm{~s}$ dados obtidos neste trabalho permitem concluir que os sabões utilizados no setor de pediatria do hospital estavam contaminados por coliformes totais, dentre eles Klebsiella pneumoniae, e podem ter sido a principal fonte de transmissão para o surto de pneumonia, embora não se possa afirmar que fossem a única causa da infecção.

Sabões contaminados não estão entre as fontes de infecções hospitalares mais citadas, mas são potencialmente perigosos, visto que normalmente esses produtos não são considerados como tal, muitas vezes não sen do analisados nas investigações de infecções hospitalares. No caso dos sabões neutros, o risco é ainda maior, pois o seu pH favorece o crescimento de microrganismos.

Evidencia-se a necessidade de uma maior fiscalização no controle de qualidade de sabões. É crescente o mercado informal de detergentes e sabões, cuja fabricação doméstica pode ser fonte de renda para diversas famílias. 0 uso de água ou matérias-primas contaminadas, química ou microbiologicamente, pode oferecer riscos aos usuários dos produtos, especialmente no caso de estar baixa a resistência do organismo. Padrões microbiológicos para o controle da qualidade de sabões, especialmente no produto final do processo de fabricação, são necessários para se evitar o risco à saúde dos consumidores. Boas práticas de fabricação devem ser implementadas e rigorosamente seguidas.

\title{
0 ccurrence of Klebsiella pneumoniaeand other coliformsin liquid neutral soap utilized in a hospital nursery
}

\author{
Abstract \\ An outbreak of hospital infection caused by K lebsiella pneumoniae has been found out in a hospital \\ nursery part of $\mathrm{H}$ ealth Service of Salvador-BA. Some microbiological analyses have been done in different
}


possible sources of exogenous contamination in order to detect the origin of the infection. The presence of Klebsiella pneumoniae and other coliforms has been verified in the soapy water utilized in the bath of newborn babies. Since no contamination in the nursery watersupply had been confirmed, several samples of the liquid neutral soap utilized have been examined, and Klebsiella pneumoniae, Enterobacter sp. and other coliforms were isolated in them. Samples of the soap from different batches were then examined, and the contamination was verified only in the batches sent to the hospital. The manufacturer attributed the contamination of those batches to the usage of non-treated water, from unknown source, in the process of soap manufacture. The results obtained in that research indicate the liquid neutral soap as a possible source of hospital infection, usually non-considered as such, and show the risks the non-observance of regular pratices of manufacture may cause to the users of hygiene and cleaning products.

Keywords Klebisiella pneumoniae - hospital infection, neutral soap, coliform - contamination.

\section{REFERÊNCIAS}

AGÊNCIA NACIONAL DE VIGILÂNCIA SAN ITÁRIA (Brasil). No Dia de Controle da Infecção H ospitalar, Anvisa chama atenção para o tema. Brasília, DF, 2001. Disponível em: $<$ http://portalweb01.saude.gov.br/saude/ aplicacoes/noticias/noticias_detal he.cfm?co seq_noticia=387>. Acesso em: 14 jan. 2006.

Portaria n. 348, de 18 de agosto de 1997. M anual de boas práticas de fabricação para produtos de higiene pessoal, cosméticos e perfumes. Brasília, DF, 1997. Disponível em: $<h t t p: / / w w w$. . anvisa.gov.br/legis/portarias/ 348_97.htm>. Acesso em: 14 jan. 2006.

\section{Resolução RDC n. 79, de 28 de agos-} to de 2000. D efinição de cosméticos e classificação de produtos. Braślia, DF, 2000. Disponível em: বhttp://www.anvisa.gov.br/legis/resol/ 2000/79_2000.pdf>. Acesso em: 14 jan. 2006.
AMERICAN
PUBLIC
HEALTH

ASSOCIATION. Standard methods for the examination of water and waste water. Washington, DC, 1975.

ARCH IBALD, L.K. et al. Serratia marcescens outbreak associated with extrinsic contamination of $1 \%$ chlorxylenol soap. Infect. Control H osp. Epidemiol., Chicago, v.18, n.10, p.704-709, 1998.

ÁVILA FIGUEROA, C. et al. Prevalencia de infecciones nosocomiales en niños: encuesta de
21 hospitales en M exico. Salud Pública Méx., Cuernavaca, v.41, p.518-525, 1999.

BRASIL. M inistério da Saúde. Portarian. 2616, de 12 de maio de 1998. Programa de controle de infecção hospitalar. Brasília, DF, 1998. Disponível em: <http://www.anvisa.gov.br/ legis/portarias/2612_98.htm>. Acesso em: 14 jan. 2006.

CONSELH O NACIONAL DE SAÚDE (Brasil). Resolução normativa n.1/78, de 27 de novembro de 1978 . N ormas sobre detergentes e seus congêneres. Brasília, DF, 1978. Disponível em: «http://www.anvisa.gov.br/legis/ resol/01_78.htm>. Acesso em: 14 jan. 2006.

FÁZIO JR., J.; N O MURA, Y.; N O GUEIRA, P.R.C. Infecção neonatal. In: FERN AN DES, A.T. et al. Infecção hospitalar e suas interfaces na área de saúde. São Paulo: Atheneu, 2000.

GONTIJO FILHO O, P.P. et al. Avaliação in vitro de alguns sabões medicinais disponíveis no Brasil. R. Bras. Cir., Rio de Janeiro, v.4, n.74, p.181-183, 1984.

KONEMAN, E. W. et al. Color atlas and textbook of diagnostic microbiology. Philadelphia: Lippincott, 1997.

LEVY, C.E. Laboratório de microbiologia. In: FERN ANDES, A.T. et al. Infecção hospitalar e suas interfaces na área de saúde. São Paulo: Atheneu, 2000. 
MAGGI, R.S.; SCHIN DLER, H.C. Etiologia bacteriana da infecção hospitalar em um hospital geral de pediatria, 1989-1990. R. IM IP, Recife, v.4, n.1, p.29-33, 1990.

MIYAGI, F.; TIMENETSKY, J.; ALTERTH U M , F. Avaliação da contaminação bacteriana em desinfetantes de uso domiciliar. R. Saúde Pública, São Paulo, v.34, n.5, p.444-448, 2000. PELCZAR, M.; REID, R.; CHAN, E.C.S. M icrobiologia. São Paulo: Makron, 1997.

PITREZ, J.L. et al. Contaminação de líquidos de infusão intravenosa: infecção hospitalar por bactérias do grupo Klebsiella-EnterobacterSerratia (KES). J. Pediatr. (Rio J.), Porto Alegre, v.52, n.3, p.18-120, 1982.
REISS, I. et al. D esinfectant contaminated with Klebsiella oxytoca as a source of sepsis in babies. Lancet, London, v.352, p.9226-9310, 2000.

SADER, H.S. et al. Perfil de sensibilidade a antimicrobianos de bactérias isoladas do trato respiratório baixo de pacientes internados em hospitais brasileiros: resultados do programa SEN TRY, 1997 e 1998. J. Pneumol., São PauIo, v.27, n.2, p.59-67, 2001.

SCH VARTSM AN, S. Produtos químicos de uso domiciliar: segurança e riscos tecnológicos. 2.ed. São Paulo: Almed, 1988.

Recebido em / Received: 16/06/06 Aceito em / Accepted: 27/09/06 